\title{
Atypical Lymph Node
}

National Cancer Institute

\section{Source}

National Cancer Institute. Atypical Lymph Node. NCI Thesaurus. Code C160779.

A lymph node that deviates from usual in terms of size, shape, and internal architecture. 